\title{
PERAN ROEPELIN DALAM MEMPERTAHANKAN EKSISTENSI PELAYARAN PERAHU PADA PERTENGAHAN PERTAMA ABAD KE-20
}

\author{
Endang Susilowati
}

Departemen Sejarah Fakultas Ilmu Budaya Universitas Diponegoro

Jl. Prof. Soedarto, S.H. Kampus Undip Tembalang - 56025

Alamat Korespondensi: endangsusilowati_aruben@yahoo.com

Diterima/ Received: 20 Desember 2015; Disetujui/ Accepted: 28 Januari 2016

\begin{abstract}
Roepelin (Roekoen Pelayaran Indonesia) coordinated activities of the perahu shipping. This was done by organizing perahu shipping to get cargos, find a market for goods carried by members of the various ports, assist members in dealing with various seaport regulations, determine shipping line, and providing capital assistance in the form of soft loans to members who lack of capital for sailing and trade. Roepelin's role has made perahu shipping still exist despite having to compete with modern marine transportation.
\end{abstract}

Keywords: Roepelin, existence of perahu shipping, inter-island shipping.

\begin{abstract}
Abstrak
Roepelin (Roekoen Pelayaran Indonesia) merupakan sebuah organisasi yang mengkoordinasikan berbagai aktivitas pelayaran perahu. Hal itu dilakukan dengan mengorganisasi pelayaran perahu untuk mendapatkan muatan, mencarikan pasaran bagi barang-barang yang dibawa oleh anggotanya dari berbagai pelabuhan, membantu para anggotanya dalam berhadapan dengan berbagai peraturan kepelabuhanan, menentukan jalur pelayaran, dan menyediakan bantuan modal dalam bentuk pinjaman lunak kepada anggota yang kekurangan modal untuk berlayar dan berdagang. Berkat peran Roepelin, pelayaran perahu tetap eksis meskipun harus bersaing dengan alat transportasi laut moderen.
\end{abstract}

Kata kunci: Roepelin, eksistensi pelayaran perahu, pelayaran antarpulau.

\section{PENDAHULUAN}

Sampai dengan penghujung abad ke-20 pelayaran perahu masih identik dengan sifat tradisional dan sederhana, dalam arti kurang mengikuti perkembangan teknologi yang terjadi dalam dunia pelayaran. Sebagian besar nakhoda atau juragan dan awak perahu tidak pernah mengenyam pendidikan pelayaran secara formal. Biasanya sejak anak-anak mereka telah ikut berlayar dan dengan cara itu mereka mendapatkan pengetahuan praktis tentang pelayaran. Pendidikan umum juga sering kali tidak sempat mereka nikmati, sehingga tidak jarang terjadi pelanggaran-pelanggaran terhadap peraturan pemerintah berkaitan dengan usaha pelayaran mereka karena mereka tidak pandai membaca dan tidak memahami peraturanperaturan yang dikeluarkan pemerintah. Ketidakpahaman tersebut tidak jarang dimanfaatkan oleh pihak-pihak yang merasa terancam dengan eksistensi pelayaran perahu, seperti perusahaan-perusahaan pelayaran milik orang-orang Tionghoa yang mengoperasikan kapal-kapal besi, dan bahkan juga perusahaan pelayaran milik pemerintah Hindia Belanda 
yaitu Koninklijk Paketvaart Maatschappij $(\mathrm{KPM}){ }^{1} \quad$ Dalam hubungan dengan para pedagang yang akan mengirimkan barang dengan perahu, tidak jarang mereka juga dipermainkan dan berakhir dengan ongkos angkut yang rendah. Mengenai hal itu surat kabar Bintang Borneo pernah menurunkan artikel yang mengungkapkan betapa lemah posisi perahu ketika berhadapan dengan pengguna jasa (Bintang Borneo, 7 Juli 1939: hlm. I; kolom 2-3). Demi untuk mendapatkan muatan, nakhoda sering kali harus mengeluarkan uang sebagai jaminan keselamatan bagi barang yang diangkutnya. Uang jaminan tersebut seharusnya dapat diterima kembali bila barang telah sampai di tempat tujuan dengan selamat. Namun demikian, yang sering terjadi adalah bahwa uang jaminan dan bahkan ongkos pengangkutan barang kadang tidak dibayarkan sesuai dengan pembicaraan pada waktu barang akan diangkut, karena penerima barang adalah pedagang lain di tempat lain pula (Collins, 1992: 17-18). Menurut Nadjamoedin Daeng Malewa apa yang dialami oleh armada perahu itu disebabkan mereka belum tergabung dalam sebuah organisasi pelayaran yang dapat memberi jalan keluar untuk berbagai permasalahan yang mereka hadapi. Apabila pelayaran perahu tetap ingin eksis, maka kehadiran sebuah organisasi yang didasari prinsip-prinsip koperasi sangat diperlukan (Malewa, t.t.: 15).

Kondisi itu melahirkan gagasan dari kaum nasionalis yang berkecimpung di bidang pelayaran perahu untuk mengkoordinasikan seluruh aktivitas pelayaran perahu dan meningkatkan perannya melalui sebuah organisasi berbentuk koperasi. Atas prakarsa Nadjamoedin Daeng Malewa yang pada waktu itu bekerja di bidang pabean ${ }^{2}$, didirikanlah badan usaha koperasi bernama Roepelin yang merupakan singkatan dari Roekoen Pelajaran Indonesia. Organisasi tersebut didirikan di Surabaya pada 1 November 1935 dan disahkan sebagai badan hukum pribumi (Inheemsch Rechtspersoon) pada 8 Juni 1936 (Melawa, t.t.: 18; Dewan Redaksi, 1990: 166; Dick, 1978: 78). ${ }^{3}$ Selanjutnya berkat bantuan R. M. Margono
Djojohadikusumo yang pada waktu itu menjabat sebagai inspektur pada Dinas Koperasi, Roepelin mendapat subsidi dari pemerintah guna menjalankan usaha koperasinya.

Berdasar pada latar belakang seperti diuraikan di depan, artikel ini akan membahas bagaimana peran Roepelin dalam upaya mempertahankan eksistensi pelayaran perahu yang semakin tersisih oleh kehadiran kapal-kapal yang sudah tergolong moderen untuk ukuran zaman itu.

\section{METODE}

Sebagai tulisan sejarah, artikel ini disusun menggunakan metode penelitian sejarah yang meliputi empat tahap, yaitu heuristik atau pengumpulan sumber, kritik sumber, interpretasi, dan historiografi atau penulisan sejarah. Sumber-sumber yang digunakan dalam tulisan ini seluruhnya adalah sumber tertulis, meliputi sumber primer dan sekunder. Pengumpulan sumber dilakukan melalui studi pustaka dan penelitian arsip.

Untuk memperoleh data yang otentik dan kredibel, dilakukan kritik eksteren dan interen terhadap sumber-sumber yang telah dikumpulkan. Sementara itu, untuk mencari pemecahan terhadap bukti-bukti sejarah yang kontradiktif dilakukan koroborasi dengan cara membandingkan dua sumber atau lebih, sehingga diperoleh fakta yang dapat dipertanggungjawabkan kebenarannya. Langkah selanjutnya adalah interpretasi terhadap fakta sejarah yang dilakukan bersamaan dengan langkah terakhir, yaitu historiografi atau penulisan sejarah.

\section{PROFIL ROEPELIN}

Roepelin beranggotakan para nakhoda perahu layar yang secara teratur mengunjungi pelabuhan Surabaya. Pada 1937 telah tercatat lebih dari 200 nakhoda yang menjadi anggota Roepelin. Sebagian besar anggotanya berasal dari Sulawesi Selatan. Perahu mereka rata-rata berukuran antara 40-100 $\mathrm{m} \rrbracket$ 
Adapun tujuan dari organisasi tersebut adalah sebagai berikut (Melawa, t.t.: 18; Dewan Redaksi, 1990:168):

1. Bersama-sama mencari muatan dengan harga (ongkos angkut) sebaik mungkin.

2. Mengusahakan secara legal keringanan dari syarat-syarat yang diwajibkan pemerintah.

3. Menyebarkan pengetahuan dan keterangan mengenai pelayaran dan hal ihwal yang berkaitan dengan itu.

4. Memotivasi para anggotanya untuk menabung.

5. Memberikan pinjaman kepada anggota untuk tujuan-tujuan yang bersifat produktif.

Tujuan yang dicanangkan oleh organisasi ini akan sangat membantu para anggotanya, mengingat pelayaran perahu merupakan salah satu jenis pelayaran yang meskipun tetap dibutuhkan kehadirannya, tetapi kurang mendapat perhatian yang memadai dari pemerintah. Hal itu antara lain terlihat dari tidak adanya perusahaan asuransi yang bersedia menjamin aktivitas pelayaran perahu ini. Perusahaan asuransi beranggapan bahwa pelayaran dengan perahu layar kayu, sekalipun kemudian juga menggunakan mesin, tetap mengandung risiko kecelakaan yang tinggi. Hal itu menjadi alasan tidak adanya perusahaan asuransi yang tertarik untuk menjamin pelayaran perahu.

Roepelin menetapkan tujuh rute pelayaran dengan Surabaya sebagai pangkalannya. Ketujuh rute tersebut adalah (Malewa, t.t.: 21-22):

1. Ke Semarang, Cirebon atau Jakarta dengan muatan kedelai, minyak kelapa, dan minyak jarak. Dalam pelayaran pulang dari Cirebon dan Semarang diangkut beras dan jagung untuk Surabaya. Dari kedua pelabuhan tersebut tidak jarang juga diangkut muatan untuk pelabuhan lain seperti Ketapang dan Pontianak.

2. Ke pelabuhan-pelabuhan di Kalimantan seperti Banjarmasin, Kota Baru, Pegatan, Balikpapan, Samarinda dan Pontianak. Untuk rute ini pelayaran ke Banjarmasin merupakan yang terpenting. Muatan yang diangkut adalah berbagai macam barang impor, beras, gula, botol kosong, dan besi tua. Pelayaran kembali ke Surabaya mengangkut kayu, kopra, dan kelapa.

3. Ke Makassar dengan muatan kopi robusta yang dibawa dari Jakarta, beras, gula, minyak tanah, dan lain-lain. Dalam pelayaran kembali ke Surabaya armada perahu mengangkut kemiri, kacang hijau, jagung, kopra, dan berbagai macam hasil hutan.

4. Ke Nusa Tenggara dengan muatan berbagai barang impor. Untuk pelayaran kembali ke Surabaya membawa muatan kopra dan buah asam.

5. Ke Palembang membawa muatan gula dan buah asam. Kebanyakan perahu yang melayari rute ini melanjutkan pelayaran ke Pulau Bangka guna mengambil pasir dan batu kerikil untuk diangkut ke Palembang.

Secara garis besar, jalur pelayaran perahu di Hindia Belanda selama 1930-an dapat dilihat pada gambar berikut.

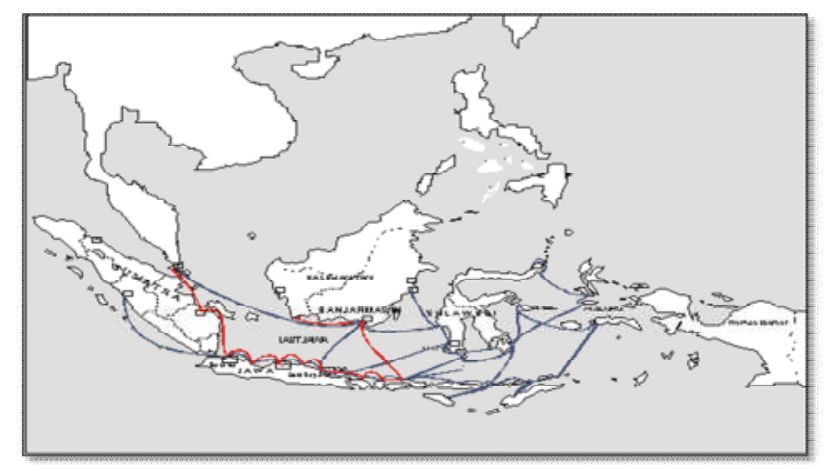

Gambar 1. Jalur Pelayaran Perahu pada Pertengahan Pertama Abad KE-20

Sumber: ANRI, Algemeen Secretary 1944-1949, Inv. Nr. 113.

Salah satu kelemahan pelayaran perahu adalah ketergantungannya pada musim dan iklim. Pada musim angin timur dapat dikatakan tidak ada masalah untuk berlayar di sepanjang musim. Namun pada pergantian dari musim timur ke musim barat sering kali cuaca tidak menentu. Kadang angin bertiup kencang atau malah berhenti sama sekali, sehingga menghambat kelancaran berlayar. Pada musim angin barat sebagian besar perahu tidak berlayar 
karena cuaca yang tidak menguntungkan. Belum adanya jaminan bagi keselamatan barang-barang yang diangkut menambah deretan kelemahan pengangkutan barang dengan perahu. $\mathrm{Hal}$ itu menyebabkan para pemilik barang-barang yang mudah rusak dalam perjalanan seperti bahan pangan mengkhawatirkan keselamatan barang mereka. Untuk meningkatkan pelayanan kepada pengguna jasa perahu, maka bagi barang-barang yang dikirim melalui Roepelin pada periode 1 April hingga 31 Oktober akan diberi jaminan atas permohonan pemilik barang. Jaminan tersebut dapat diberikan apabila pemilik barang mengalami kerugian total selama barang diangkut ke tempat tujuan atau barang rusak karena perahu tenggelam, terdampar, terbakar, dan sebagainya. Untuk periode 1 November sampai 31 Maret, jaminan hanya diberikan apabila pemilik barang mengalami kerugian total selama pengangkutan barang (Malewa, t.t.: 22). Pemberian jaminan seperti itu sebenarnya sudah banyak dilakukan oleh para nakhoda perahu Bugis, terutama yang berlayar ke Makassar dan Banjarmasin. Para nakhoda biasanya membayar sejumlah uang kepada pengirim barang sebagai jaminan untuk keamanan barang-barang yang dikirim. Mereka akan mendapat surat perintah bayar dari pengirim barang yang ditujukan kepada penerima barang. Apabila barang sudah diserahkan kepada penerima barang dalam keadaan seperti ketika dikirim, maka nakhoda akan memperoleh kembali uang jaminan yang dibayarkan sebelum barang diangkut, ditambah dengan ongkos pengangkutan barang tersebut.

Roepelin memang belum menjangkau seluruh masyarakat pelayaran perahu yang ada di Indonesia. Bagi perahu-perahu yang tidak melayari rute sampai ke pelabuhan Surabaya (seperti misalnya armada perahu yang berpangkalan di Makassar dan hanya melayari wilayah bagian timur Indonesia saja) tentu tidak dapat menjadi anggota Roepelin. ${ }^{4}$ Meskipun demikian kehadirannya telah membawa semangat baru di lingkungan masyarakat pelayaran perahu setelah sekian lama pelayaran perahu berada dalam kondisi tertekan akibat beroperasinya kapal uap milik KPM. Roepelin tidak hanya mengorganisasi armada perahu untuk mendapatkan muatan saja, tetapi juga mencarikan pasaran bagi barang-barang yang dibawa oleh anggotanya dari berbagai pelabuhan. Kecuali itu Roepelin juga membantu para anggotanya dalam berhadapan dengan berbagai peraturan kepelabuhanan yang sering tidak dipahami oleh para nakhoda. Roepelin pun menyediakan bantuan modal dalam bentuk pinjaman lunak kepada anggota yang kekurangan modal untuk berlayar dan berdagang. Semua itu sangat membantu masyarakat pelayaran perahu yang mulai bangkit untuk berperan kembali dalam pengangkutan barang antarpulau. Berkat Roepelin dan usaha kaum nasionalis yang duduk dalam Volksraad, banyak pihak, terutama pemerintah, mulai memberi perhatian pada pelayaran perahu. $\mathrm{Hal}$ itu pantas diterima oleh masyarakat pelayaran perahu karena sektor tersebut telah sangat berperan dalam memberi lapangan pekerjaan, khususnya bagi masyarakat yang memiliki sumber daya manusia marginal.

Upaya Roepelin tersebut sudah mulai menampakkan hasilnya tidak lama setelah organisasi ini berdiri. Pada 1936, ketika Roepelin baru saja berdiri, jumlah kargo yang diangkut armada perahu ke pelabuhan Makassar secara keseluruhan adalah sebesar 93.000 ton. Pada 1937 dan 1938 jumlah itu meningkat masingmasing menjadi 109.400 ton dan 114.800 ton (Dick, 1987: 115). Pada 1937 dari 286 perahu anggota Roepelin (jumlah ini hanya sekitar 2\% dari total perahu yang masuk ke pelabuhan Surabaya) telah mengangkut kargo sebanyak 7.550 ton, suatu jumlah yang cukup signifikan bagi perdagangan dengan perahu antara pelabuhan-pelabuhan Surabaya, Makassar, dan Banjarmasin (Dick, 1987: 78). Meskipun tidak semua perahu yang datang ke pelabuhan Makassar adalah perahu anggota Roepelin, tetapi mengingat jaringan pelayaran antara pelabuhan Surabaya, Makassar, dan Banjarmasin merupakan jalur perahu yang terpadat di antara jalur pelayaran perahu-perahu Roepelin lainnya, tidak mustahil bila peningkatan kargo perahu yang 
terjadi di pelabuhan Makassar pada waktu itu antara lain adalah berkat usaha Roepelin.

\section{CATATAN}

${ }^{1}$ Op ten Noort sebagai direktur pertama KPM sejak awal sudah mengkhawatirkan keberadaan perahu layar yang ia sebut sebagai 'armada semut'. Lihat ARA Den Haag, Koleksi Arsip KPM Inv. Nr. 80: Missive van de Hoofdagenten de KPM aan den Raad van Bestuur der KPM te Amsterdam.Singapore (SS Camphuys), 29 September 1890'.

${ }^{2}$ Nadjamoedin Daeng Malewa adalah seorang nasionalis yang pada 1946/1947 menjadi Perdana Menteri pertama Negara Indonesia Timur.

${ }^{3}$ Roepelin dibentuk dengan dukungan Partai Bangsa Indonesia (PBI) yang kemudian menjadi Parindra setelah berfusi dengan Budi Utomo. Permasalahan yang dihadapi oleh masyarakat pelayaran perahu menjadi salah satu agenda dalam kongres PBI ke III pada 1934 di Malang. Kongres tersebut berhasil membentuk sebuah komisi yang bertugas menginvestigasi permasalahan-permasalahan yang dihadapi oleh pelayaran perahu. Setelah memelajari berbagai permasalahan yang ada, komisi tersebut merekomendasi pembentukan semacam kantor penasihat yang akan membantu para pemilik perahu dan para nakhoda dalam berhadapan dengan formalitas pabean dan pelabuhan. Kantor tersebut didirikan di Surabaya pada 10 September 1934. Penggagas berdirinya kantor penasihat itu adalah Nadjamoedin Daeng Malewa yang pada kongres PBI merupakan wakil dari Partai Sarekat Selebes.

${ }^{4}$ Bagi armada perahu yang melayari rute-rute di wilayah timur Indonesia seperti Maluku dan lebih banyak berpangkalan di pelabuhan Makassar sehingga jarang masuk ke pelabuhan Surabaya, dimungkinkan untuk mendirikan organisasi serupa di Makassar.

\section{SIMPULAN}

Sepanjang sejarahnya, pelayaran perahu memiliki dinamika yang sangat menarik untuk dikaji. Armada pelayaran perahu yang sering dijuluki "armada semut" itu telah menunjukkan kemampuannya sebagai salah satu alat transportasi laut yang cukup tangguh. Bagi negara Indonesia yang sebagian besar wilayahnya berupa perairan, pelayaran perahu telah memainkan peranan penting dalam menunjang terciptanya jaringan transportasi laut antarpulau, khususnya untuk pulau-pulau kecil dan terpencil yang tidak mungkin dijangkau oleh kapal-kapal besar. Dalam perkembangannya pelayaran perahu juga memainkan peranan penting dalam perdagangan antarpulau secara umum di Indonesia.

Berbagai upaya dari masyarakat pelayaran perahu telah dilakukan untuk memajukan pelayaran perahu. Pembentukan Roepelin pada 1936 dan kemudian Pelra (Pelayaran Rakyat) sejak 1964 merupakan usaha untuk tetap mempertahankan eksistensi pelayaran perahu di perairan Indonesia. Motorisasi yang dipelopori oleh pemerintah pada awal 1970-an pun dimaksudkan untuk mempersiapkan perahu agar bisa bersaing dengan armada pelayaran moderen yang tidak bisa dihindari kehadirannya.

\section{REFERENSI}

ARA Den Haag, Koleksi Arsip KPM Inv. Nr. 80: Missive van de Hoofdagenten de KPM aan den Raad van Bestuur der KPM te Amsterdam. Singapore (SS Camphuys), 29 September 1890'.

Bintang Borneo, 7 Juli 1939, hlm. I, kolom 2-3.

Collins, G. E. P. (1992). Makassar Sailing. Singapore: Oxford University Press.

Dewan Redaksi/Tim Penulis Puspindo (1990). Sejarah Pelayaran Niaga di Indonesia, Jilid I. Jakarta: Yayasan Pusat Studi Pelayaran Niaga di Indonesia.

Dick, H. W. "Prahu Shipping in Eastern Indonesia Part I". Bulletin of Indonesian Economic Studies, Vol. XI, No.2, July 1975. "Prahu Shipping in Eastern Indonesia in the Interwar Period", Bulletin of Indonesian Economic Studies, Vol. 23, No.1, April 1987.

Malewa, Nadjamoedin Daeng (t.t.). De Indonesische Prauwvaart in het Interinsulair Verkeer. Surabaya: tanpa penerbit.

(t.t.). Roekoen Pelayaran Indonesia (ROEPELIN 1935-1936). Surabaya: tanpa penerbit. 